\title{
THE DISTRIBUTION OF DEUTERATED FORMALDEHYDE WITHIN ORION-KL
}

\author{
Cécile Favre $^{1}$, Edwin A. Bergin ${ }^{1}$, Justin L. Neill ${ }^{1}$, Nathan R. Crockett ${ }^{2}$, Qizhou Zhang ${ }^{3}$, and Dariusz C. Lis ${ }^{4,5}$ \\ ${ }_{1}^{1}$ Department of Astronomy, University of Michigan, 500 Church Street, Ann Arbor, MI 48109, USA; cfavre@umich.edu \\ ${ }^{2}$ California Institute of Technology, Division of Geological and Planetary Sciences, MS 150-21, Pasadena, CA 91125, USA \\ ${ }^{3}$ Harvard-Smithsonian Center for Astrophysics, 60 Garden Street, Cambridge, MA 02138, USA
${ }^{4}$ LERMA, Observatoire de Paris, PSL Research University, CNRS, Sorbonne Universités, UPMC Univ. Paris 06, F-75014, Paris, France \\ ${ }^{5}$ Cahill Center for Astronomy and Astrophysics 301-17, California Institute of Technology, Pasadena, CA 91125, USA \\ Received 2015 January 5; accepted 2015 June 19; published 2015 July 29
}

\begin{abstract}
We report the first high angular resolution imaging $\left(3^{\prime \prime} .4 \times 3^{\prime \prime} .0\right)$ of deuterated formaldehyde (HDCO) toward Orion-KL, carried out with the Submillimeter Array. We find that the spatial distribution of the formaldehyde emission systematically differs from that of methanol: while methanol is found toward the inner part of the region, $\mathrm{HDCO}$ is found in colder gas that wraps around the methanol emission on four sides. The $\mathrm{HDCO} / \mathrm{H}_{2} \mathrm{CO}$ ratios are determined to be 0.003-0.009 within the region, up to an order of magnitude higher than the D/H measured for methanol. These findings strengthen the previously suggested hypothesis that there are differences in the chemical pathways leading to HDCO (via deuterated gas-phase chemistry) and deuterated methanol (through conversion of formaldehyde into methanol on the surface of icy grain mantles).
\end{abstract}

Key words: astrochemistry - ISM: abundances - ISM: individual objects (Orion-KL) - ISM: molecules line: identification

\section{INTRODUCTION}

The Orion-KL nebula, which lies at a distance of $414 \pm 7 \mathrm{pc}$ (Menten et al. 2007), is a focal source for studies of the physics and chemistry of high-mass star forming regions. Its rich molecular diversity and complex physical structure have been revealed by a number of spectral line surveys and interferometric studies of the region (e.g., Blake et al. 1987; Schilke et al. 1997, 2001; Beuther et al. 2005, 2006; Comito et al. 2005; Persson et al. 2007; Friedel \& Snyder 2008; Guélin et al. 2008; Tercero et al. 2010, 2011; Favre et al. 2011a, 2011b, 2014; Friedel \& Widicus Weaver 2012; Widicus Weaver \& Friedel 2012; Brouillet et al. 2013; Esplugues et al. 2013; Peng et al. 2013). Recently, a broadband spectral line survey of Orion-KL carried out with the Herschel/HIFI spectrometer (Bergin et al. 2010; Crockett et al. 2010, 2014) has been obtained as part of the HEXOS key program. ${ }^{6}$ The unprecedented $1.2 \mathrm{THz}$ wide frequency coverage of this survey has allowed for strong constraints on physical parameters and molecular abundances due to the detection of many transitions for each molecule with a wide range of excitation conditions, revealing the presence of thermal gradients (e.g., Wang et al. 2011). Among the molecular components associated with Orion-KL lie the so-called Hot Core and Compact Ridge. Although the precise nature of these regions remains enigmatic, evidence has been recently provided that they may have originated from the interaction of the remnants of a recent explosion with ice grains mantles ( $\leqslant 720$ years ago, e.g., Gómez et al. 2005, 2008; Rodríguez et al. 2005; Bally et al. 2011; Nissen et al. 2012), leading to the evaporation and the heating of organic material (Favre et al. 2011a; Zapata et al. 2011).

Deuterium fractionation is intrinsically a low-temperature process. Therefore, deuterated molecules in warm $(T \geqslant 100 \mathrm{~K})$ regions, such as Orion-KL, offer a window into its physical conditions at the earlier, colder stage $(T \sim 10-30 \mathrm{~K})$ when this

\footnotetext{
www.hexos.org
}

material likely formed (Blake et al. 1987; Pagani et al. 1992; Charnley et al. 1997). Numerous deuterated species have been observed toward Orion-KL: deuterated water (Turner et al. 1975; Jacq et al. 1990; Neill et al. 2013b), deuterated ammonia (Rodriguez Kuiper et al. 1978; Walmsley et al. 1987), deuterated formaldehyde (Loren \& Wootten 1985; Turner 1990), and deuterated methanol (Mauersberger et al. 1988; Jacq et al. 1993; Peng et al. 2012). Recently, Neill et al. (2013a) used the HIFI survey and tens of transitions to set strong constraints in the $\mathrm{D} / \mathrm{H}$ ratio of organics associated with Orion-KL. Their finding strongly suggests that $\mathrm{D} / \mathrm{H}$ fractionation is inhomogenuous in this source.

In this study, we extend the HIFI study of deuterated species performed by Neill et al. (2013a, 2013b); especially since the Herschel observations are spatially unresolved, even with welldetermined column densities within the beam, there can be large deviations in the deuterium fractionation as a function of spatial position. In Section 2, we present the Submillimeter Array (SMA) observations to complement the HIFI analysis. In particular, we focus on formaldehyde $\left(\mathrm{H}_{2} \mathrm{CO}\right.$ and $\left.\mathrm{HDCO}\right)$. The $\mathrm{D} / \mathrm{H}$ ratios of this molecule is key to obtaining a full picture of the oxygen chemistry in this region, as formaldehyde is believed to be an intermediate in the grain-surface synthesis of methanol through sequential reactions of $\mathrm{H}$ or $\mathrm{D}$ atoms with CO (see Watanabe \& Kouchi 2002; Cazaux et al. 2011; Taquet et al. 2012). Alternatively, gas-phase chemistry might independently lead to the formation of formaldehyde via reactions involving $\mathrm{CH}_{2} \mathrm{D}^{+}$products under warmer conditions (typically $T>50 \mathrm{~K}$, see Loren \& Wootten 1985; Wootten 1987). Incidentally, the tentative detection of the $\mathrm{CH}_{2} \mathrm{D}^{+}$ion toward Orion-KL by Roueff et al. (2013) suggests that gasphase chemistry might be efficient for the HDCO formation. In this analysis, we present the first high angular resolution image of the spatial distribution of (deuterated) formaldehyde in Orion-KL and discuss the different chemical pathways that can be involved in its formation. More specifically, results and analysis are presented in Section 3 and discussed in Section 4, with conclusions set out in Section 5. 
Table 1

Spectroscopic and Observational Line Parameters for Formaldehyde ${ }^{\mathrm{a}, \mathrm{b}}$

\begin{tabular}{|c|c|c|c|c|c|c|c|c|c|c|c|c|c|c|c|}
\hline \multicolumn{16}{|c|}{ HDCO } \\
\hline \multirow{3}{*}{$\begin{array}{l}\text { Frequency } \\
(\mathrm{MHz})\end{array}$} & \multirow[t]{3}{*}{ Transition } & \multirow{3}{*}{$\begin{array}{l}E_{\text {up }} \\
(\mathrm{K})\end{array}$} & \multirow{3}{*}{$\begin{array}{c}A \\
\times 10^{-4} \\
\left(\mathrm{~s}^{-1}\right)\end{array}$} & \multirow{2}{*}{\multicolumn{2}{|c|}{$\frac{\text { Synthesized }}{\text { Beam }}$}} & \multicolumn{5}{|c|}{$\mathrm{dF} 1$} & \multicolumn{5}{|c|}{$\mathrm{dF} 2$} \\
\hline & & & & & & \multirow{2}{*}{$\begin{array}{c}\int T_{\mathrm{mb}} d v \\
\left(\mathrm{~K} \mathrm{~km} \mathrm{~s}^{-1}\right)\end{array}$} & \multirow{2}{*}{$\begin{array}{c}v_{\mathrm{LSR}} \\
\left(\mathrm{km} \mathrm{s}^{-1}\right)\end{array}$} & \multirow{2}{*}{$\begin{array}{c}\Delta v_{\mathrm{LSR}} \\
\left(\mathrm{km} \mathrm{s}^{-1}\right)\end{array}$} & \multirow{2}{*}{$\begin{array}{l}T_{\mathrm{ex}} \\
(\mathrm{K})\end{array}$} & \multirow{2}{*}{$\begin{array}{c}N \\
\left(10^{14} \mathrm{~cm}^{-2}\right)\end{array}$} & \multirow{2}{*}{$\begin{array}{c}\int T_{\mathrm{mb}} \mathrm{dv} \\
\left(\mathrm{K} \mathrm{km} \mathrm{s}^{-1}\right)\end{array}$} & \multirow{2}{*}{$\begin{array}{c}v_{\mathrm{LSR}} \\
\left(\mathrm{km} \mathrm{s}^{-1}\right)\end{array}$} & \multirow{2}{*}{$\begin{array}{c}\Delta v_{\mathrm{LSR}} \\
\left(\mathrm{km} \mathrm{s}^{-1}\right)\end{array}$} & \multirow{2}{*}{$\begin{array}{l}T_{\mathrm{ex}} \\
(\mathrm{K})\end{array}$} & \multirow{2}{*}{$\begin{array}{c}N \\
\left(10^{14} \mathrm{~cm}^{-2}\right)\end{array}$} \\
\hline & & & & $\left(" x^{\prime \prime}\right)$ & $\overline{\mathrm{PA}\left({ }^{\circ}\right)}$ & & & & & & & & & & \\
\hline $192893.26^{\mathrm{c}, \mathrm{d}}$ & $3_{0,3}-2_{0,2}$ & 18.5 & 1.94 & $\cdots$ & $\cdots$ & $\cdots$ & $\cdots$ & $\cdots$ & $\ldots$ & $\ldots$ & $\cdots$ & $\cdots$ & $\cdots$ & $\cdots$ & $\cdots$ \\
\hline 193907.46 & $3_{2,1}-2_{2,0}$ & 50.4 & 1.10 & $3.44 \times 3.01$ & 30 & $8.50(1.54)$ & $9.84(0.14)$ & $1.80(0.46)$ & $89(16)$ & $4.65(0.86)$ & $7.38(0.43)$ & $7.75(0.10)$ & $2.20(0.18)$ & $56(7)$ & $2.92(0.22)$ \\
\hline \multirow[t]{3}{*}{193391.61} & $3_{2,2}-2_{2,1}$ & 50.4 & 1.09 & $3.47 \times 3.02$ & 30 & $9.05(0.63)$ & $9.65(0.10)$ & $1.69(0.16)$ & $89(16)$ & $4.96(0.37)$ & $7.07(0.35)$ & $7.57(0.07)$ & $2.40(0.15)$ & $56(7)$ & $2.80(0.18)$ \\
\hline & & & & & & \multicolumn{5}{|c|}{$\mathrm{dF} 3$} & \multicolumn{5}{|c|}{$\mathrm{dF} 4$} \\
\hline & & & & & & $\begin{array}{c}\int T_{\mathrm{mb}} \mathrm{dv} \\
\left(\mathrm{K} \mathrm{km} \mathrm{s}^{-1}\right)\end{array}$ & $\begin{array}{c}v_{\mathrm{LSR}} \\
\left(\mathrm{km} \mathrm{s}^{-1}\right)\end{array}$ & $\begin{array}{c}\Delta v_{\mathrm{LSR}} \\
\left(\mathrm{km} \mathrm{s}^{-1}\right)\end{array}$ & $\begin{array}{l}T_{\mathrm{ex}} \\
(\mathrm{K})\end{array}$ & $\begin{array}{c}\mathrm{N} \\
\left(10^{14} \mathrm{~cm}^{-2}\right)\end{array}$ & $\begin{array}{c}\int T_{\mathrm{mb}} \mathrm{dv} \\
\left(\mathrm{K} \mathrm{km} \mathrm{s}^{-1}\right)\end{array}$ & $\begin{array}{c}v_{\mathrm{LSR}} \\
\left(\mathrm{km} \mathrm{s}^{-1}\right)\end{array}$ & $\begin{array}{c}\Delta v_{\mathrm{LSR}} \\
\left(\mathrm{km} \mathrm{s}^{-1}\right)\end{array}$ & $\begin{array}{l}T_{\mathrm{ex}} \\
(\mathrm{K})\end{array}$ & $\begin{array}{c}\mathrm{N} \\
\left(10^{14} \mathrm{~cm}^{-2}\right)\end{array}$ \\
\hline $192893.26^{\mathrm{c}, \mathrm{d}}$ & $3_{0,3}-2_{0,2}$ & 18.5 & 1.94 & $\cdots$ & $\cdots$ & $\cdots$ & $\cdots$ & $\ldots$ & $\ldots$ & $\ldots$ & $\cdots$ & $\ldots$ & $\cdots$ & $\cdots$ & $\cdots$ \\
\hline 193907.46 & $3_{2,1}-2_{2,0}$ & 50.4 & 1.10 & $3.44 \times 3.01$ & 30 & $7.13(0.98)$ & $7.80(0.10)$ & $1.71(0.32)$ & $57(8)$ & $2.77(0.42)$ & $11.25(1.45)$ & $8.61(0.05)$ & $1.13(0.14)$ & $52(8)$ & $4.26(0.62)$ \\
\hline 193391.61 & $3_{2,2}-2_{2,1}$ & 50.4 & 1.09 & $3.47 \times 3.02$ & 30 & $8.00(2.29)$ & $8.00(0.03)$ & $1.39(0.44)$ & $57(8)$ & $3.12(0.93)$ & $9.79(1.02)$ & $8.30(0.10)$ & $1.66(0.24)$ & $52(8)$ & $3.71(0.45)$ \\
\hline
\end{tabular}

$($ para- $) \mathrm{H}_{2}{ }^{13} \mathrm{CO}$

\begin{tabular}{|c|c|c|c|c|c|c|c|c|c|c|c|c|c|c|c|}
\hline \multirow{3}{*}{$\begin{array}{l}\text { Frequency } \\
(\mathrm{MHz})\end{array}$} & \multirow[t]{3}{*}{ Transition } & \multirow{3}{*}{$\begin{array}{l}E_{\text {up }} \\
(\mathrm{K})\end{array}$} & \multirow{3}{*}{$\begin{array}{c}A \\
\times 10^{-4} \\
\left(\mathrm{~s}^{-1}\right)\end{array}$} & \multirow{2}{*}{\multicolumn{2}{|c|}{$\begin{array}{c}\text { Synthesized } \\
\text { beam }\end{array}$}} & \multicolumn{5}{|c|}{$\mathrm{dF} 1$} & \multicolumn{5}{|c|}{$\mathrm{dF} 2$} \\
\hline & & & & & & \multirow{2}{*}{$\begin{array}{c}\int T_{\mathrm{mb}} \mathrm{dv} \\
\left(\mathrm{K} \mathrm{km} \mathrm{s}^{-1}\right)\end{array}$} & \multirow{2}{*}{$\begin{array}{c}v_{\mathrm{LSR}} \\
\left(\mathrm{km} \mathrm{s}^{-1}\right)\end{array}$} & \multirow{2}{*}{$\begin{array}{c}\Delta v_{\mathrm{LSR}} \\
\left(\mathrm{km} \mathrm{s}^{-1}\right)\end{array}$} & \multirow{2}{*}{$\begin{array}{l}T_{\mathrm{ex}} \\
(\mathrm{K})\end{array}$} & \multirow{2}{*}{$\begin{array}{c}\mathrm{N} \\
\left(10^{14} \mathrm{~cm}^{-2}\right)\end{array}$} & \multirow{2}{*}{$\begin{array}{c}\int T_{\mathrm{mb}} \mathrm{dv} \\
\left(\mathrm{K} \mathrm{km} \mathrm{s}^{-1}\right)\end{array}$} & \multirow{2}{*}{$\begin{array}{c}v_{\mathrm{LSR}} \\
\left(\mathrm{km} \mathrm{s}^{-1}\right)\end{array}$} & \multirow{2}{*}{$\begin{array}{c}\Delta v_{\mathrm{LSR}} \\
\left(\mathrm{km} \mathrm{s}^{-1}\right)\end{array}$} & \multirow{2}{*}{$\begin{array}{l}T_{\mathrm{ex}} \\
(\mathrm{K})\end{array}$} & \multirow{2}{*}{$\begin{array}{c}\mathrm{N} \\
\left(10^{14} \mathrm{~cm}^{-2}\right)\end{array}$} \\
\hline & & & & $\left(" x^{\prime \prime}\right)$ & PA $\left(^{\circ}\right)$ & & & & & & & & & & \\
\hline 212811.18 & $3_{0,3}-2_{0,2}$ & 20.4 & 2.64 & $3.17 \times 2.75$ & 30 & $17.99(1.73)$ & $9.88(0.09)$ & $1.83(0.24)$ & $89(16)$ & $5.44(0.53)$ & $16.04(1.37)$ & $7.44(0.11)$ & $2.54(0.29)$ & $56(7)$ & $2.83(0.26)$ \\
\hline $213037.34^{\mathrm{d}}$ & $3_{2,2}-2_{2,1}$ & 67.7 & 1.46 & $\ldots$ & $\cdots$ & $\ldots$ & $\ldots$ & $\ldots$ & $\ldots$ & $\ldots$ & $\ldots$ & $\ldots$ & $\ldots$ & $\cdots$ & $\ldots$ \\
\hline \multirow[t]{3}{*}{213293.57} & $3_{2,1}-2_{2,0}$ & 67.7 & 1.46 & $3.15 \times 2.75$ & 30 & $5.87(0.85)$ & $9.89(0.19)$ & $2.21(0.42)$ & $89(16)$ & $5.43(0.82)$ & $3.84(0.40)$ & $7.43(0.13)$ & $2.16(0.30)$ & $56(7)$ & $2.83(0.35)$ \\
\hline & & & & & & \multicolumn{5}{|c|}{ dF3 } & \multicolumn{5}{|c|}{$\mathrm{dF} 4$} \\
\hline & & & & & & $\begin{array}{c}\int T_{\mathrm{mb}} \mathrm{dv} \\
\left(\mathrm{K} \mathrm{km} \mathrm{s}^{-1}\right)\end{array}$ & $\begin{array}{c}v_{\mathrm{LSR}} \\
\left(\mathrm{km} \mathrm{s}^{-1}\right)\end{array}$ & $\begin{array}{c}\Delta v_{\mathrm{LSR}} \\
\left(\mathrm{km} \mathrm{s}^{-1}\right)\end{array}$ & $\begin{array}{l}T_{\mathrm{ex}} \\
(\mathrm{K})\end{array}$ & $\begin{array}{c}\mathrm{N} \\
\left(10^{14} \mathrm{~cm}^{-2}\right)\end{array}$ & $\begin{array}{c}\int T_{\mathrm{mb}} \mathrm{dv} \\
\left(\mathrm{K} \mathrm{km} \mathrm{s}^{-1}\right)\end{array}$ & $\begin{array}{c}v_{\mathrm{LSR}} \\
\left(\mathrm{km} \mathrm{s}^{-1}\right)\end{array}$ & $\begin{array}{c}\Delta v_{\mathrm{LSR}} \\
\left(\mathrm{km} \mathrm{s}^{-1}\right)\end{array}$ & $\begin{array}{l}T_{\mathrm{ex}} \\
(\mathrm{K})\end{array}$ & $\begin{array}{c}\mathrm{N} \\
\left(10^{14} \mathrm{~cm}^{-2}\right)\end{array}$ \\
\hline 212811.18 & $3_{0,3}-2_{0,2}$ & 20.4 & 2.64 & $3.17 \times 2.75$ & 30 & $12.93(0.28)$ & $7.94(0.03)$ & $1.55(0.04)$ & $57(8)$ & $2.27(0.64)$ & $9.70(1.16)$ & $8.44(0.03)$ & $1.58(0.25)$ & $52(8)$ & $1.58(0.20)$ \\
\hline $213037.34^{\mathrm{d}}$ & $3_{2,2}-2_{2,1}$ & 67.7 & 1.46 & $\ldots$ & $\ldots$ & $\ldots$ & $\ldots$ & $\ldots$ & $\ldots$ & $\ldots$ & $\ldots$ & $\ldots$ & $\ldots$ & $\ldots$ & $\ldots$ \\
\hline 213293.57 & $3_{2,1}-2_{2,0}$ & 67.7 & 1.46 & $3.15 \times 2.75$ & 30 & $3.14(0.55)$ & $8.03(0.08)$ & $1.56(0.37)$ & $57(8)$ & $2.27(0.44)$ & $2.16(0.26)$ & $8.63(0.17)$ & $1.30(0.23)$ & $52(8)$ & $1.58(0.23)$ \\
\hline
\end{tabular}

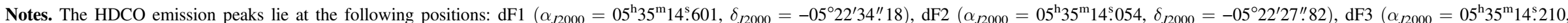

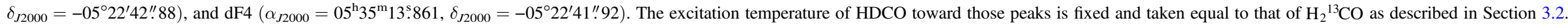

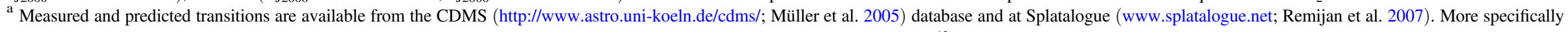

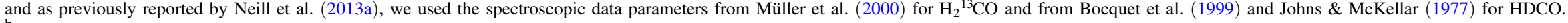

${ }^{\mathrm{b}}$ The numbers in brackets refer to the $1 \sigma$ level uncertainty.

${ }^{\mathrm{c}, \mathrm{d}}$ These two lines have been excluded from our analysis since their emission is contaminated by the emission from $\mathrm{HCOOCH}_{3}$ and ${ }^{33} \mathrm{SO}_{\text {, respectively. }}$ 


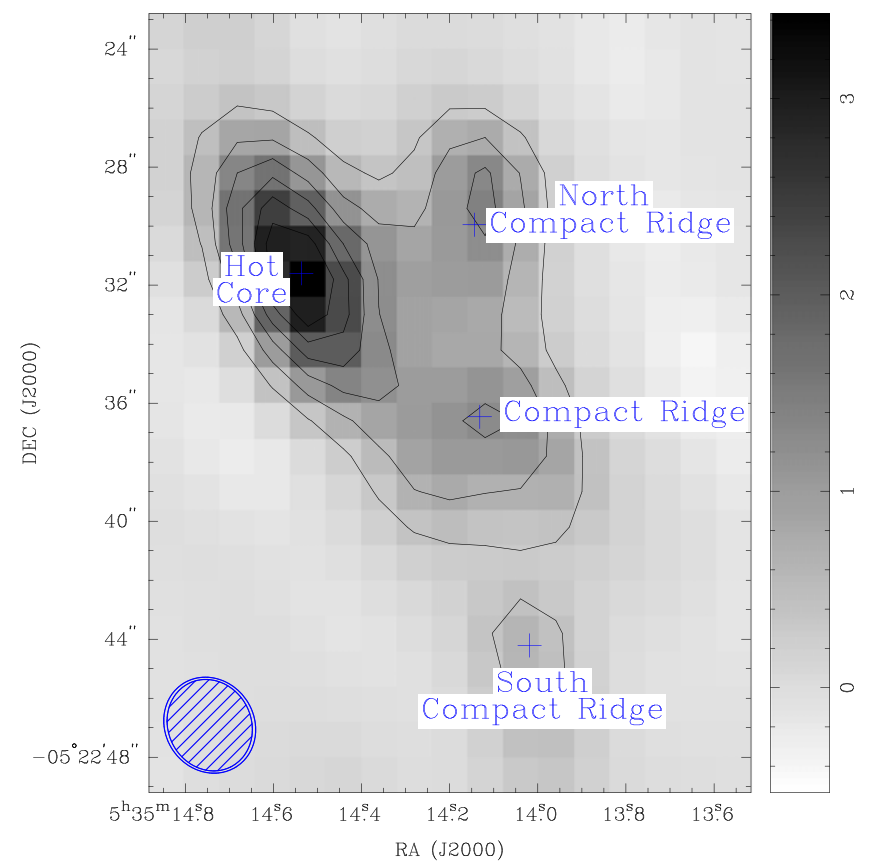

Figure 1. Continuum emission maps obtained at $213 \mathrm{GHz}$ (grayscale, USB band) and at $198 \mathrm{GHz}$ (black, LSB band) toward Orion-KL as measured with the SMA. The first contour and the level step are at $3 \sigma$ (where $1 \sigma=0.132 \mathrm{Jy} \mathrm{beam}^{-1}$ ). The synthesized beams are $3 " .2 \times 2$. 8 (P.A. $=$ $26: 7$ ) and $3 " .5 \times 3$ ". 01 (P.A. $=32: 7$ ) at 207 and $198 \mathrm{GHz}$, respectively. Blue crosses mark the positions of the four main continuum sources derived from Gaussian fits in the $(u, v)$ plane $(198 \mathrm{GHz}$ data set, LSB band). These sources are the Hot core $\left(\alpha_{J 2000}=05^{\mathrm{h}} 35^{\mathrm{m}} 14^{\mathrm{s}} .537, \delta_{J 2000}=-05^{\circ} 22^{\prime} 31^{\prime \prime} .600\right)$, the Compact Ridge $\left(\alpha_{J 2000}=05^{\mathrm{h}} 35^{\mathrm{m}} 14^{\mathrm{s}} .132, \delta_{J 2000}=-05^{\circ} 22^{\prime} 36^{\prime \prime} .462\right)$, the North Compact Ridge $\left(\alpha_{J 2000}=05^{\mathrm{h}} 35^{\mathrm{m}} 14^{\mathrm{s}} .144, \delta_{J 2000}=-05^{\circ} 22^{\prime} 29^{\prime \prime} .295\right)$, and the South Compact Ridge $\left(\alpha_{J 2000}=05^{\mathrm{h}} 35^{\mathrm{m}} 14^{\mathrm{s}} .019, \delta_{J 2000}=-05^{\circ} 22^{\prime} 44^{\prime \prime} .212\right)$.

\section{OBSERVATIONS AND DATA REDUCTION}

Observations of Orion-KL were carried out with the $\mathrm{SMA}^{7}$ (Ho et al. 2004) in its compact configuration on 2013 December 12 for about $6.75 \mathrm{hr}$. The phase-tracking center was $\alpha_{J 2000}=05^{\mathrm{h}} 35^{\mathrm{m}} 14^{\mathrm{s}} .20, \delta_{J 2000}=-05^{\circ} 22^{\prime} 33^{\prime \prime}$.00. The new broader-bandwidth SMA capability of the $230 \mathrm{GHz}$ band was used to cover the following frequency ranges: 192.6-194.6 GHz and $197.6-199.6 \mathrm{GHz}$ in LSB band, and 207.6-209.6 GHz and 212.6-214.6 GHz in the USB band. An enormous advantage of this broadband capability is the possibility to observe transitions of both $\mathrm{HDCO}$ and $\mathrm{H}_{2}{ }^{13} \mathrm{CO}$ in a single tuning (see Table 1 ). The correlator was configured with a uniform spectral resolution over $4 \mathrm{GHz}$ bandwidth in each sideband. Each $4 \mathrm{GHz}$ bandwidth is divided into 48 "chunks" and each chunk is further divided into 128 channels with a channel width of $0.812 \mathrm{MHz}$. The weather conditions were good and stable with an atmospheric opacity of about 0.14 at $225 \mathrm{GHz}$. The SMA data were calibrated using the MIR/IDL package ${ }^{8}$ (Qi 2007). The nearby quasars 0423-013 and $0510+180$ were used as complex gain (phase and amplitude) calibrators.

Continuum subtraction and data imaging were performed using the MIRIAD software package. The final continuum emission maps obtained at 198 and $213 \mathrm{GHz}$ are shown in

7 The SMA is a joint project between the Smithsonian Astrophysical Observatory and the Academia Sinica Institute of Astronomy and Astrophysics, and is funded by the Smithsonian Institution and the Academia Sinica. https://www.cfa.harvard.edu/ cqi/mircook.html
Figure 1. They were restored using a robust weighting of 0.0 , resulting in a synthesized beam size of $3^{\prime \prime} .5 \times 3^{\prime \prime} .01$ (P.A. = $32: 7$ ) at $198 \mathrm{GHz}$ and of $3 " .2 \times 2^{\prime \prime} .8$ (P.A. $=26: 7$ ) at $213 \mathrm{GHz}$. Positions of the four main continuum sources derived from Gaussian fits in the $(u, v)$ LSB data set image plane are given in Figure 1. The positions of these continuum sources are commensurate between the LSB and USB data sets and, in agreement, within the synthesized beam size, with previous PdBI observations (Favre et al. 2011a).

In this analysis, we only focus on two emission lines of $\mathrm{HDCO}$ and two of para- $-\mathrm{H}_{2}{ }^{13} \mathrm{CO}$ (see spectroscopic parameters listed in Table 1). The spectral resolution is $1.14 \mathrm{~km} \mathrm{~s}^{-1}$ for $\mathrm{H}_{2}{ }^{13} \mathrm{CO}$ at $212 / 213 \mathrm{GHz}$ and $1.26 \mathrm{~km} \mathrm{~s}^{-1}$ for the HDCO lines at $193 \mathrm{GHz}$. The resulting synthesized beam sizes $\left(\sim 3^{\prime \prime} \times 3^{\prime \prime}\right.$, P.A. $\left.=30^{\circ}\right)$ are given in Table 1 at the different frequencies.

\section{RESULTS AND ANALYSIS}

\subsection{Emission Maps and Velocity Structure}

The $\mathrm{HDCO}$ and $\mathrm{H}_{2}{ }^{13} \mathrm{CO}$ emission maps integrated over the line profile are shown in Figure 2. Four main molecular emission peaks, labeled $\mathrm{dF} 1$ to $\mathrm{dF} 4$, are associated with the HDCO emission. More specifically, they are located toward the left of the Hot Core component $(\mathrm{dF} 1)$, north of the Compact Ridge (dF2), and in the quiescent ridge (dF3 and dF4) located south of the Compact Ridge. Their coordinates are given in Table 1 . The regions $\mathrm{dF} 1, \mathrm{dF} 2$, and $\mathrm{dF} 3$ are also associated with the $\mathrm{H}_{2}{ }^{13} \mathrm{CO}$ emission, but $\mathrm{dF} 4$ is not. Incidentally, it is important to note that the integrated emission map of the $\mathrm{H}_{2}{ }^{13} \mathrm{CO}$ transition at $213293.57 \mathrm{MHz}$ is strongly contaminated by the emission from an unidentified species toward the Hot Core region. This is shown in Figure 3, which displays the integrated emission map along with the spectrum of this $\mathrm{H}_{2}{ }^{13} \mathrm{CO}$ line; the latter being taken at the position of the contaminated emission peak.

The spectra of the formaldehyde transitions observed toward regions $\mathrm{dF} 1$ to $\mathrm{dF} 4$ are shown in Figure 4 and the observed line parameters are summarized in Table 1 . The bulk of the formaldehyde emission toward those peaks appears to lie between $v_{\mathrm{LSR}}=7.5 \mathrm{~km} \mathrm{~s}^{-1}$ and $v_{\mathrm{LSR}}=9.8 \mathrm{~km} \mathrm{~s}^{-1}$. This result is consistent with the HDCO LSR velocity derived by Loren \& Wootten (1985) toward the quiescent ridge $\left(\sim 8.5 \mathrm{~km} \mathrm{~s}^{-1}\right.$, single-dish Millimeter Wave Observatory observations) and by Neill et al. (2013a) toward the region $\left(\sim 8\right.$ and $10.4 \mathrm{~km} \mathrm{~s}^{-1}$, Herschel/HIFI observations). It is important to note that Neill et al. (2013a) associated the HDCO emission with two velocity components in the Compact Ridge. This difference results from the fact that (i) some complex molecules, such as methyl formate or dimethyl ether, are seen with two distinct velocity components emitting at $\sim 7.5$ and $9.2 \mathrm{~km} \mathrm{~s}^{-1}$ in the Compact Ridge (e.g., Favre et al. 2011a; Brouillet et al. 2013), and that (ii) the Herschel observations are spatially unresolved. We infer that the two HDCO velocity components seen by Neill et al. (2013a) actually correspond to our HDCO emission observed toward $\mathrm{dF} 3$ and $\mathrm{dF} 1$, respectively.

\subsection{Excitation Temperature}

Assuming optically thin emission, we use the integrated line intensity measurements of the observed $\mathrm{H}_{2}{ }^{13} \mathrm{CO}$ transitions to derive the formaldehyde excitation temperature $\left(T_{\mathrm{ex}}\right)$ within 

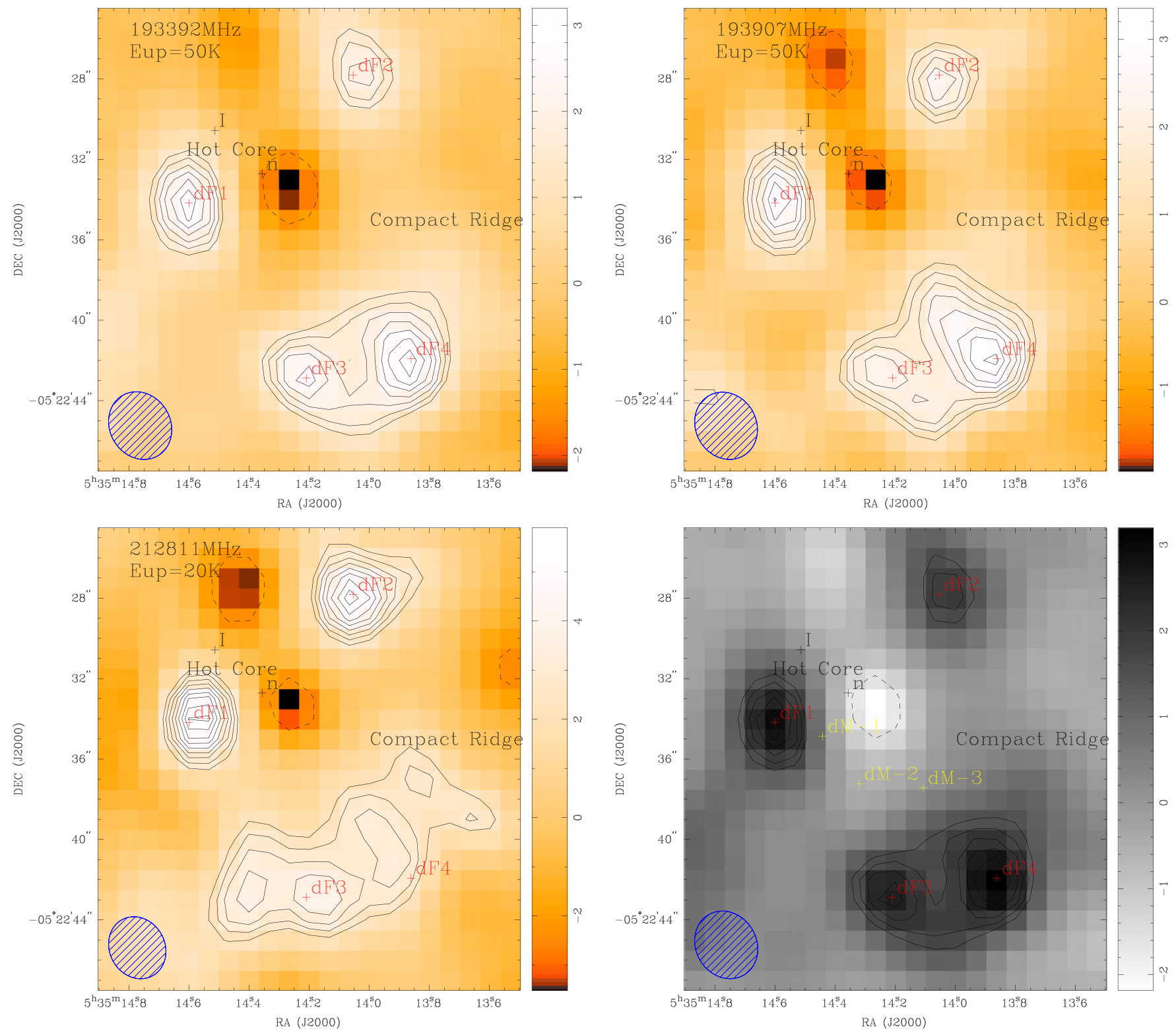

Figure 2. Formaldehyde integrated emission maps from $v_{\mathrm{LSR}}=6.5 \mathrm{~km} \mathrm{~s}^{-1}$ to $v_{\mathrm{LSR}}=10.0 \mathrm{~km} \mathrm{~s}^{-1}$. Red crosses indicate the position of the regions dF1 to $\mathrm{dF} 4$. Black crosses indicate the positions of the radio source I $\left(\alpha_{J 2000}=05^{\mathrm{h}} 35^{\mathrm{m}} 14^{\mathrm{s}} .5141, \delta_{J 2000}=-05^{\circ} 22^{\prime} 30^{\prime \prime} .575\right)$ and the IR source $\mathrm{n}\left(\alpha_{J 2000}=05^{\mathrm{h}} 35^{\mathrm{m}} 14^{\mathrm{s}} .3571, \delta_{J 2000}=-05^{\circ}\right.$ 22'32".719; Goddi et al. 2011b). Top: $\mathrm{HDCO}$ emission at $193391.6 \mathrm{MHz}$ (left panel) and $193907.5 \mathrm{MHz}$ (right panel). Bottom left: $\mathrm{H}_{2}{ }^{13} \mathrm{CO}$ emission at 212811.2 MHz. The first contour is at $5 \sigma$ and the level step at $1 \sigma$ (where $\sigma=0.27$ and $0.44 \mathrm{Jy} \mathrm{beam}^{-1} \mathrm{~km} \mathrm{~s}^{-1}$ for $\mathrm{HDCO}$ and $\mathrm{H}_{2}{ }^{13} \mathrm{CO}$, respectively). Bottom right: same as the top left panel, expect for the indicated deuterated methanol emission peaks (in yellow) identified by Peng et al. (2012).

Orion-KL following Equation (1):

$$
T_{\mathrm{ex}}=-\frac{h \nu}{k_{\mathrm{B}} \ln \left(\frac{g_{l} A_{l} \nu_{u}^{2} W_{u}}{g_{u} A_{u} \nu_{l}^{2} W_{l}}\right)}=-\frac{E_{u}-E_{l}}{\ln \left(\frac{g_{l} A_{l} \nu_{u}^{2} W_{u}}{g_{u} A_{u} \nu_{l}^{2} W_{l}}\right)},
$$

where $E, W, A, g$, and $\nu$ refer to the state energies $(\mathrm{K})$, the integrated line intensities $\left(\mathrm{K} \mathrm{km} \mathrm{s}^{-1}\right)$, the Einstein $A$ coefficients $\left(\mathrm{s}^{-1}\right)$, the statistical weights, and the line frequencies $(\mathrm{Hz})$ of the $3_{2,1}-2_{2,0}(u)$ and $3_{0,3}-2_{0,2}(l)$ transitions. It is important to note that Equation (1) cannot be directly applied to HDCO since both of the detected transitions have the same upper energy level (see Table 1). Thus, the below analysis hinges on the assumption that $T_{\mathrm{ex}}$ is the same for both HDCO and $\mathrm{H}_{2}{ }^{13} \mathrm{CO}$.

Figure 5(a) presents the excitation temperature map for $\mathrm{H}_{2}{ }^{13} \mathrm{CO}$ within Orion-KL. The formaldehyde excitation temperature derived toward the $\mathrm{dF} 2, \mathrm{dF} 3$, and $\mathrm{dF} 4$ peaks is low $(52-57 \mathrm{~K}$, see Table 1$)$, contrary to $\mathrm{dF} 1$ for which it is higher $(\sim 90 \mathrm{~K})$. Our derived temperatures in the quiescent ridge (i.e., regions $\mathrm{dF} 3$ and $\mathrm{dF} 4$ ) are commensurate within the uncertainties with that derived by Bergin et al. (1994, $60 \pm 30 \mathrm{~K}$ ) using $\mathrm{CH}_{3} \mathrm{C}_{2} \mathrm{H}$, a known tracer of ambient ridge gas. Regarding the $\mathrm{dF} 2$ emission peak, our derived temperature is in agreement with a KL-W methanol clump that lies in its vicinity (i.e., $\sim 2^{\prime \prime}$ east, see Peng et al. 2012). As for the dF1 emission peak, there is a slight discrepancy with the temperature derived by Peng et al. (2012). In particular, these 

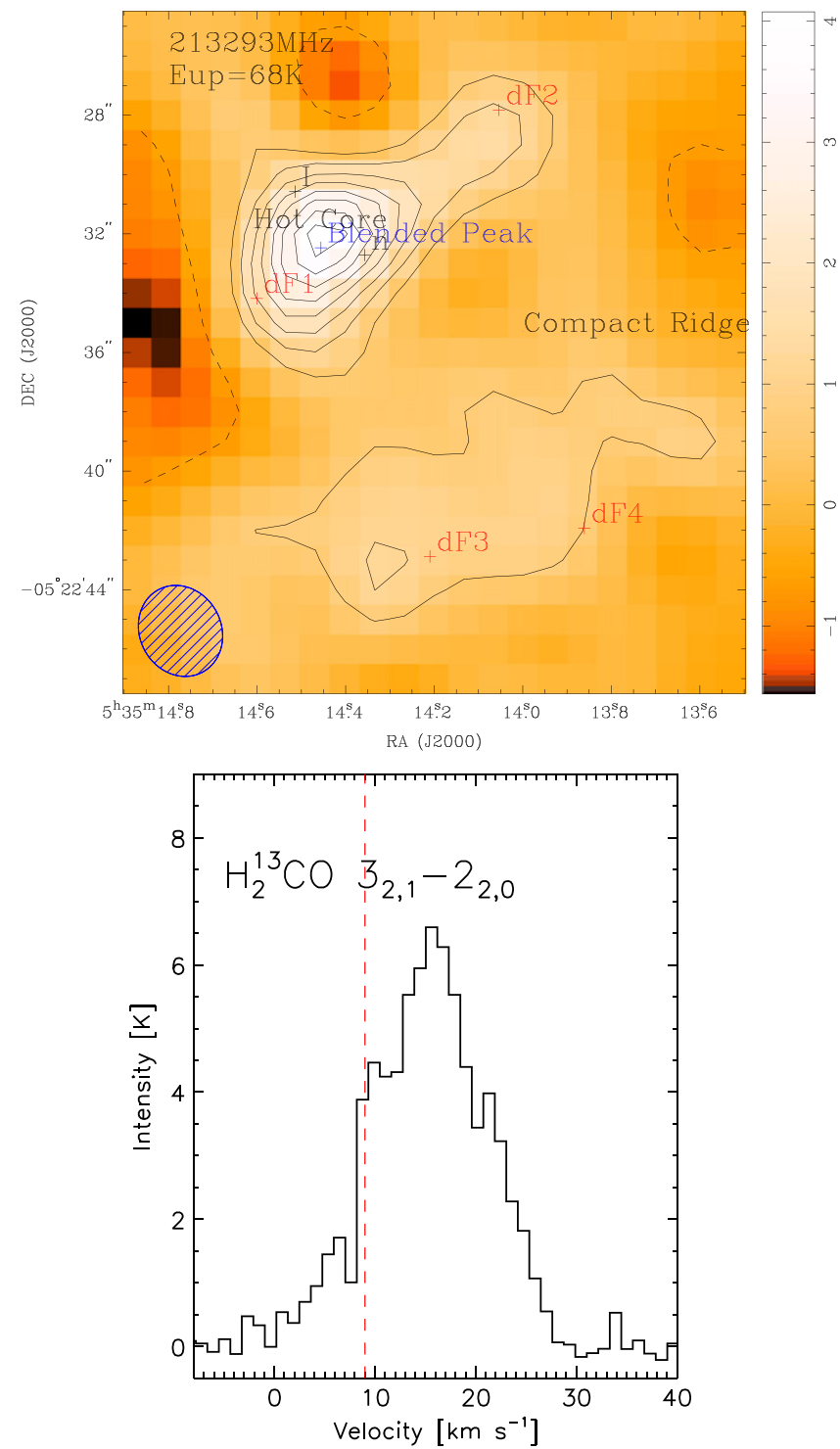

Figure 3. Top: $\mathrm{H}_{2}{ }^{13} \mathrm{CO}$ integrated emission map at $213293.6 \mathrm{MHz}$ from $v_{\mathrm{LSR}}=6.5 \mathrm{~km} \mathrm{~s}^{-1}$ to $v_{\mathrm{LSR}}=10.0 \mathrm{~km} \mathrm{~s}^{-1}$. Red crosses indicate the position of the regions $\mathrm{dF} 1$ to $\mathrm{dF} 4$ while black crosses indicate the positions of the radio source I and the IR source $\mathrm{n}$ (see Figure 2). The first contour is at $3 \sigma$ and the level step is at $2 \sigma$ (where $\sigma=0.27 \mathrm{Jy}_{\text {beam }}{ }^{-1} \mathrm{~km} \mathrm{~s}^{-1}$ ). The emission of this $\mathrm{H}_{2}{ }^{13} \mathrm{CO}$ transition is strongly contaminated by the emission from an unidentified species toward the Hot Core region marked by a blue cross and labeled "Blended Peak." Bottom: $\mathrm{H}_{2}{ }^{13} \mathrm{CO}$ spectrum observed toward the "Blended Peak" position (blue cross). The red dashed line indicates an LSR velocity of $9.0 \mathrm{~km} \mathrm{~s}^{-1}$.

authors report a temperature that is lower than the typical temperature derived in the vicinity of this region $(\sim 100-300 \mathrm{~K}$, e.g., Friedel \& Snyder 2008; Favre et al. 2011a; Goddi et al. 2011a). However, looking at their Figure B.4., a $130 \mathrm{~K}$ temperature seems to be consistent with their data, suggesting that their error bars might have been underestimated. Overall the temperatures derived here are lower than the typical temperatures derived for organic species toward the Hot Core and Compact Ridge components associated with the inner part of Orion-KL (e.g., Crockett et al. 2014).

\subsection{Column Density}

Assuming that (i) LTE is reached, which implies that the excitation temperature is equal to the rotational temperature, and (ii) the rotational temperature is the same for both HDCO and $\mathrm{H}_{2}{ }^{13} \mathrm{CO}$, we derive the total column density, $N$, by using the following equation (Goldsmith \& Langer 1999):

$$
\ln \left(\frac{8 \pi k_{\mathrm{B}} \nu^{2} W}{g_{u} h c^{3} A_{u l}}\right)=\ln \left(\frac{N}{Q}\right)-\frac{E_{u}}{T},
$$

where

$\begin{array}{ll}W & \text { is the integrated line intensity }\left(\mathrm{K} \mathrm{cm} \mathrm{s}^{-1}\right), \\ \nu & \text { is the line frequency }(\mathrm{Hz}), \\ A_{u l} & \text { is the Einstein coefficient }\left(\mathrm{s}^{-1}\right), \\ g_{u} & \text { is the statistical weight, } \\ N & \text { is the total column density }\left(\mathrm{cm}^{-2}\right), \\ Q & \text { is the partition function, } \\ E_{\mathrm{up}} & \text { is the upper state energy }(\mathrm{K}), \\ h & \text { is the Planck constant }(\mathrm{erg} \mathrm{s}), \\ k_{\mathrm{B}} & \text { is the Boltzmann constant }\left(\mathrm{erg} \mathrm{K}^{-1}\right), \\ c & \text { is the speed of light }\left(\mathrm{cm} \mathrm{s}^{-1}\right), \text { and } \\ T & \text { is the excitation temperature derived above } \\ & \text { (in K, Section 3.2). }\end{array}$

The column densities derived toward regions $\mathrm{dF} 1$ to $\mathrm{dF} 4$ for both $\mathrm{HDCO}$ and para- $\mathrm{H}_{2}{ }^{13} \mathrm{CO}$ are listed in Table 1. In addition, Table 2 gives the total column densities for $\mathrm{HDCO}, \mathrm{H}_{2}{ }^{13} \mathrm{CO}$, and $\mathrm{H}_{2} \mathrm{CO}$ toward the $\mathrm{dF} 1$ to $\mathrm{dF} 4$ peaks. The total column densities have been calculated as follow: (i) the column densities derived for the two HDCO transitions, which are listed in Table 1, have been averaged. The same applies to the two para- $\mathrm{H}_{2}{ }^{13} \mathrm{CO}$ transitions. (ii) Regarding $\mathrm{H}_{2}{ }^{13} \mathrm{CO}$ and HDCO, we assume an ortho:para ratio of $3: 1$, which is commensurate with measurements performed toward Orion-KL by Kahane et al. (1984) and Crockett et al. (2014), and a ${ }^{12} \mathrm{C} /{ }^{13} \mathrm{C}$ isotopic ratio of 70 (see Favre et al. 2014 and reference therein), which is in agreement within the error bars with previous studies (e.g., Persson et al. 2007; Stahl et al. 2008).

\subsection{D/H Ratios for Formaldehyde}

Using the total column densities for $\mathrm{HDCO}$ and $\mathrm{H}_{2}{ }^{13} \mathrm{CO}$ (see Section 3.3 and Table 2), we derive the $\mathrm{D} / \mathrm{H}$ ratio for regions $\mathrm{dF} 1$ to $\mathrm{dF} 4$. The resulting $\mathrm{D} / \mathrm{H}$ ratios are given in Table 2 . Figure 5(b) shows the distribution map of the $\mathrm{D} / \mathrm{H}$ ratio for formaldehyde in Orion-KL. The $\mathrm{HDCO} / \mathrm{H}_{2} \mathrm{CO}$ ratio is found to be $0.009 \pm 0.002$ toward $\mathrm{dF} 4,0.003 \pm 0.001$ toward $\mathrm{dF} 1$, and $0.004 \pm 0.001$ and $0.005 \pm 0.002$ toward $\mathrm{dF} 2$ and $\mathrm{dF} 3$, respectively. Our results are commensurate within the uncertainties from previous $\mathrm{D} / \mathrm{H}$ ratio measurements in the region (e.g., Loren \& Wootten 1985; Neill et al. 2013a) and suggest a possible gradient in the $\mathrm{HDCO} / \mathrm{H}_{2}{ }^{13} \mathrm{CO}$ ratio at the $3 \sigma$ level.

\section{DISCUSSION}

\subsection{Anticorrelation between Formaldehyde and Methanol Emission}

A recent study by Peng et al. (2012) using the Plateau de Bure interferometer derived the $\mathrm{D} / \mathrm{H}$ ratios of methanol $\left(\mathrm{CH}_{2} \mathrm{DOH}\right.$ and $\left.\mathrm{CH}_{3} \mathrm{OD}\right)$ at comparable resolution to our 


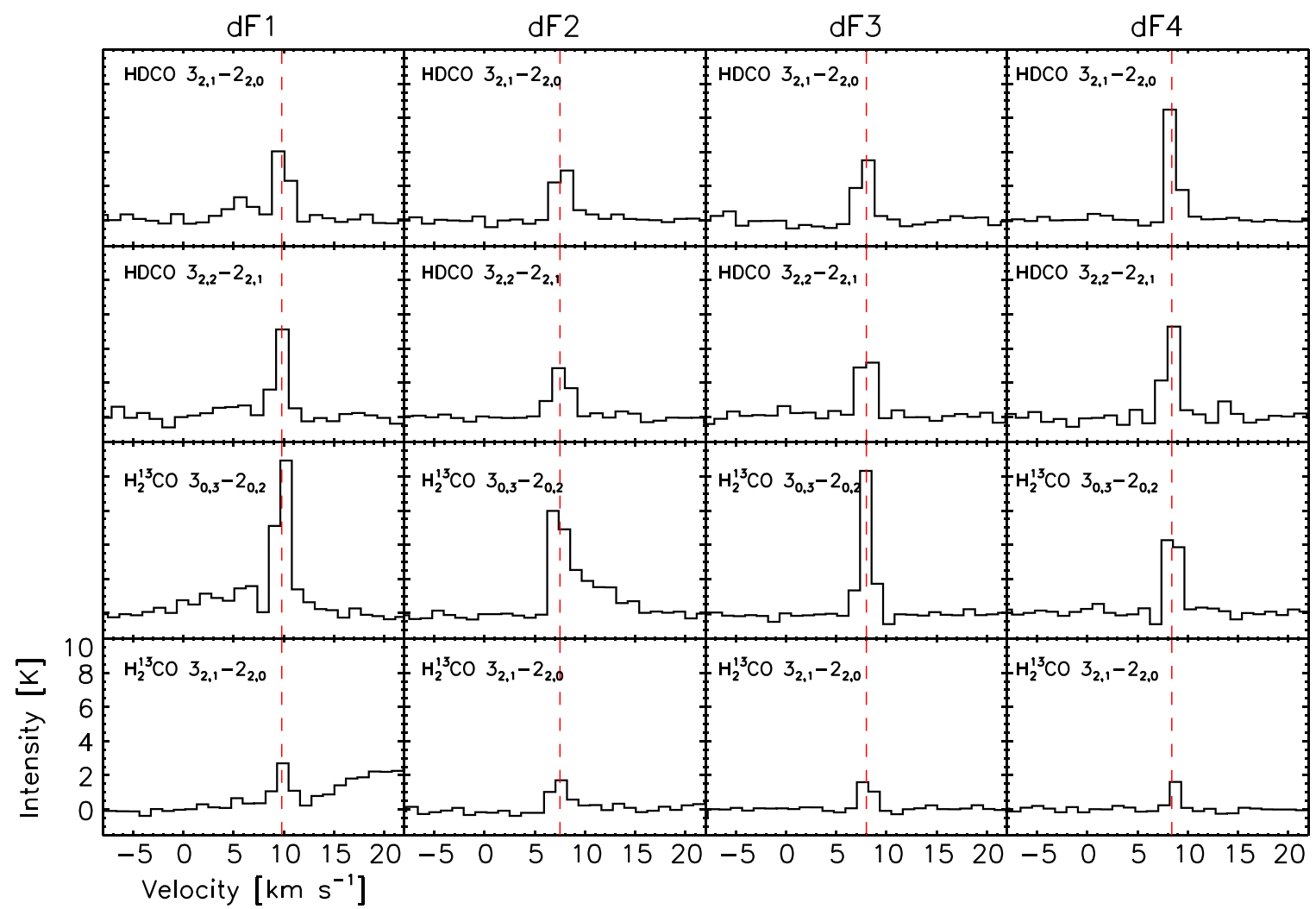

Figure 4. $\mathrm{HDCO}$ and $\mathrm{H}_{2}{ }^{13} \mathrm{CO}$ spectra observed toward $\mathrm{dF} 1, \mathrm{dF} 2, \mathrm{dF} 3$, and $\mathrm{dF} 4$. The red dashed line indicates the $v_{\mathrm{LSR}}$ toward each peak (i.e., 9.8, 7.5, 8.0, and $8.4 \mathrm{~km} \mathrm{~s}^{-1}$, respectively).

SMA observations. A notable result is that the spatial distribution of formaldehyde emission ( $\mathrm{HDCO}$ and $\mathrm{H}_{2}{ }^{13} \mathrm{CO}$, see Figure 2) clearly differs from that of (deuterated) methanol (see Figure 3 of Peng et al. 2012). The methanol distribution follows a V-shaped structure linking the Hot Core component to the Compact Ridge (Peng et al. 2012) while formaldehyde exhibits a spatial structure which appears to surround this molecular V-shaped structure on four sides. This difference is illustrated in Figure 2 (bottom right panel) in which the deuterated methanol emission peaks identified by Peng et al. (2012) are indicated on the HDCO integrated emission map at at $193391.6 \mathrm{MHz}$. Furthermore, the $\mathrm{D} / \mathrm{H}$ ratio for methanol derived by Peng et al. (2012) lies in the range $(0.8-1.3) \times 10^{-3}$, which is up to an order of magnitude (within the uncertainties) lower than the $\mathrm{D} / \mathrm{H}$ ratio for formaldehyde derived in this study (see Table 2).

\subsection{Origin of Formaldehyde Emission}

All the nearby well-characterized sources (i.e., Hot Core and Compact Ridge) are not coincident with formaldehyde emission. In fact, it is possible and even likely that we are seeing quiescent material surrounding the hotter sources, such as the well-known quiescent ridge in Orion-KL. Incidentally, the spatial difference between the formaldehyde and methanol emission has already been observed toward others sources, such as the Horsehead Photon-dominated Region (PDR) and its associated dense core (Guzmán et al. 2013) and the Orion Bar PDR (Leurini et al. 2006, 2010). In their respective analyses, the authors have shown that the UV radiation field affects the gas-phase abundance of formaldehyde and methanol. More specifically, the $\mathrm{H}_{2} \mathrm{CO} / \mathrm{CH}_{3} \mathrm{OH}$ abundance ratio is expected to be higher in high-FUV illuminated environments compared with denser and less illuminated regions. In this light, the entire Orion-KL quiescent ridge gas is a face-on PDR (see Irvine et al. 1987; Persson et al. 2007; Lerate et al. 2008), and therefore the photodissociation of gas-phase methanol into formaldehyde might occur (e.g., see, Le Teuff et al. 2000; Leurini et al. 2006, 2010). In this context, we determine the abundance ratio of $\mathrm{H}_{2} \mathrm{CO} / \mathrm{CH}_{3} \mathrm{OH}$ in the formaldehyde clumps. Comparison to ratios measured toward other PDRs would then illuminate whether the Orion PDR is influencing the local chemistry of dense material surrounding the hot embedded cores.

The determination of the methanol column density (see Equation (2)) relies on the assumptions that the $\mathrm{CH}_{3} \mathrm{OH}-\mathrm{E}$ transitions listed in Table 3 are optically thin and that the rotational temperature is the same as that of $\mathrm{H}_{2}{ }^{13} \mathrm{CO}$. It is important to note that toward the $\mathrm{dF} 1$ and $\mathrm{dF} 2$ emission peaks, the $\mathrm{CH}_{3} \mathrm{OH}-\mathrm{E}$ lines are strongly blended (see Figure 6), preventing us from deriving the column density of methanol at those positions. Regarding the $\mathrm{dF} 3$ and $\mathrm{dF} 4$ regions, the resulting $\mathrm{H}_{2} \mathrm{CO} / \mathrm{CH}_{3} \mathrm{OH}$ abundance ratio lies in the range 3.5-4.5, which might suggest a slight decrease in the methanol abundance in the quiescent ridge. However, our derived ratio is lower by at least a factor of 3-400 compared with that estimated by Leurini et al. (2010) toward the Orion Bar, suggesting that the production of formaldehyde in Orion-KL through the photodissociation of gas-phase methanol is not the main formation route. Finally, it is noteable that our estimated $\mathrm{H}_{2} \mathrm{CO} / \mathrm{CH}_{3} \mathrm{OH}$ abundance ratio is more consistent with that found in hot-corino regions (see Maret et al. 2004, 2005 and Guzmán et al. 2013 for a review). This finding leads us to 

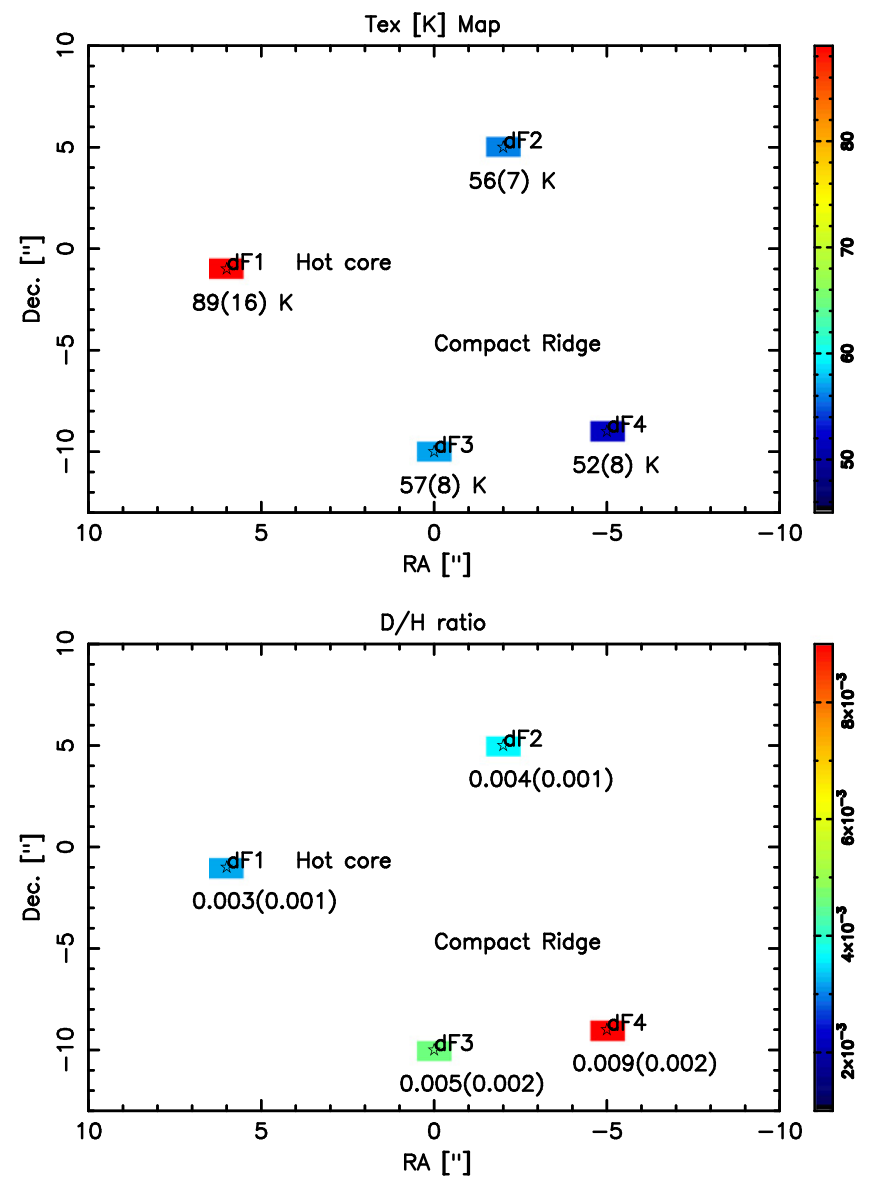

Figure 5. Top: $\mathrm{H}_{2}{ }^{13} \mathrm{CO}$ excitation temperature map toward Orion-KL. Bottom: $\mathrm{D} / \mathrm{H}$ ratio for formaldehyde within Orion-KL.

argue that formaldehyde emission in Orion-KL is more likely probing the edge of the hot gas.

\subsection{Implications: On the Formaldehyde Formation}

Formaldehyde and methanol are believed to be formed on ice grain mantles during the pre-stellar cold phase $(T<50 \mathrm{~K})$ from successive hydrogenation reactions of $\mathrm{H}$ or $\mathrm{D}$ atoms with CO (see, e.g., Charnley et al. 1997; Watanabe \& Kouchi 2002; Cazaux et al. 2011; Taquet et al. 2012):

$$
\mathrm{CO} \rightarrow \mathrm{HCO} \rightarrow \mathrm{H}_{2} \mathrm{CO} \rightarrow \mathrm{CH}_{3} \mathrm{O} \rightarrow \mathrm{CH}_{3} \mathrm{OH}
$$

and

$$
\mathrm{CO} \rightarrow \mathrm{DCO} \rightarrow \mathrm{HDCO} \rightarrow \mathrm{CH}_{2} \mathrm{DO} \rightarrow \mathrm{CH}_{2} \mathrm{DOH} .
$$

Table 3

Spectroscopic Parameters of the $\mathrm{CH}_{3} \mathrm{OH}-\mathrm{E}$ Methanol Transitions Observed with the SMA Towards the dF3 and dF4 Emission Peaks ${ }^{\mathrm{a}}$

\begin{tabular}{lccc}
\hline \hline $\begin{array}{l}\text { Frequency } \\
(\mathrm{MHz})\end{array}$ & Transition & $\begin{array}{l}E_{\mathrm{up}} \\
(\mathrm{K})\end{array}$ & $\begin{array}{c}A \\
\left(\times 10^{-5} \mathrm{~s}^{-1}\right)\end{array}$ \\
\hline 193415.37 & $4_{0,4}-3_{0,3} v_{t}=0$ & 36.3 & 3.03 \\
193441.61 & $4_{1,4}-3_{1,3} v_{t}=0$ & 28.8 & 2.84 \\
193474.33 & $4_{3,1}-3_{3,0} v_{t}=0$ & 70.9 & 1.33 \\
193488.99 & $4_{3,2}-3_{3,1} v_{t}=0$ & 85.9 & 1.33 \\
193506.60 & $4_{1,3}-3_{1,2} v_{t}=0$ & 44.3 & 2.91 \\
\hline
\end{tabular}

Note.

${ }^{a}$ Measured and predicted transitions are available from the CDMS database (Müller et al. 2005) and at Splatalogue (www.splatalogue.net, Remijan et al. 2007).

Laboratory experiments have shown that the sequential $\mathrm{CO}$ hydrogenation process (i.e., Reaction (3)) efficiently forms both formaldehyde and methanol at low temperatures $(\leqslant 20 \mathrm{~K}$, see Hidaka et al. 2004; Watanabe et al. 2004; Fuchs et al. 2009). Thus, if methanol and formaldehyde both purely originate from ice grain mantles, the measured $\mathrm{D} / \mathrm{H}$ ratio should be similar (within a factor of two) for both molecules, and, in particular, these molecules should trace similar environments while desorbed as they share a common origin. This is inconsistent with our observations (see Section 4.1), and thus strongly argues in favor of differences in the chemical formation pathways of these deuterated molecules. Thus, $\mathrm{CH}_{3} \mathrm{OH}$ and $\mathrm{H}_{2} \mathrm{CO}$ emission is probing different spatial regions within the central region of Orion-KL that may not be coeval. We infer that a likely scenario is HDCO production through hot gas-phase deuterium chemistry in the colder gas associated with Orion-KL, as suggested by Loren \& Wootten (1985). More specifically, at relatively high temperatures $(T \sim$ 70-100 K, Wootten 1987; Öberg et al. 2012), such as that derived in this study (see Figure 5), reaction (5) is active due to its high exothermicity ( $\Delta \mathrm{E}$ of $654 \mathrm{~K}$, see Roueff et al. 2013) and favors deuterium fractionation through reactions involving $\mathrm{CH}_{2} \mathrm{D}^{+}$as a parent molecule (Favre et al. 2015):

$$
\mathrm{CH}_{3}^{+}+\mathrm{HD} \leftrightarrows \mathrm{CH}_{2} \mathrm{D}^{+}+\mathrm{H}_{2}+\Delta \mathrm{E}
$$

In that context, reaction (5) can then lead to the formation of $\mathrm{HDCO}$ and $\mathrm{H}_{2} \mathrm{CO}$ (see further details in Loren \& Wootten 1985). Incidentally, the temperature of this colder region associated with Orion-KL is not sufficient to desorb $\mathrm{CH}_{3} \mathrm{OH}$ from the surface of icy grain mantles $(T \geqslant 120-160 \mathrm{~K}$; see

Table 2

Total Formaldehyde Column Densities and D/H Ratios

\begin{tabular}{lcccc}
\hline \hline Position & $\begin{array}{c}\mathrm{N}(\mathrm{HDCO}) \\
\left(\times 10^{14} \mathrm{~cm}^{-2}\right)\end{array}$ & $\begin{array}{c}\mathrm{N}\left(\mathrm{H}_{2}^{13} \mathrm{CO}\right) \\
\left(\times 10^{14} \mathrm{~cm}^{-2}\right)\end{array}$ & $\begin{array}{c}\mathrm{N}\left(\mathrm{H}_{2} \mathrm{CO}\right) \\
\left(\times 10^{16} \mathrm{~cm}^{-2}\right)\end{array}$ \\
\hline $\mathrm{dF} 1$ & $4.81(0.62)$ & $21.70(2.72)$ & $15.20(1.90)$ & $\mathrm{D} / \mathrm{H} \mathrm{Ratio}$ \\
$\mathrm{dF} 2$ & $2.86(0.20)$ & $11.30(1.22)$ & $7.92(0.86)$ & $0.0032(0.0008)$ \\
$\mathrm{dF} 3$ & $2.94(0.67)$ & $9.06(1.00)$ & $6.34(0.70)$ & $0.0036(0.0006)$ \\
$\mathrm{dF} 4$ & $3.99(0.54)$ & $6.34(0.85)$ & $4.44(0.60)$ & $0.0046(0.0016)$ \\
\hline
\end{tabular}

Note. The total $\mathrm{H}_{2}^{13} \mathrm{CO}$ and $\mathrm{H}_{2} \mathrm{CO}$ column densities have been derived assuming an ortho:para ratio of 3:1 (e.g., see Kahane et al. 1984; Crockett et al. 2014) and a ${ }^{12} \mathrm{C} /{ }^{13} \mathrm{C}$ isotopic ratio of 70 (e.g., see, Favre et al. 2014). 


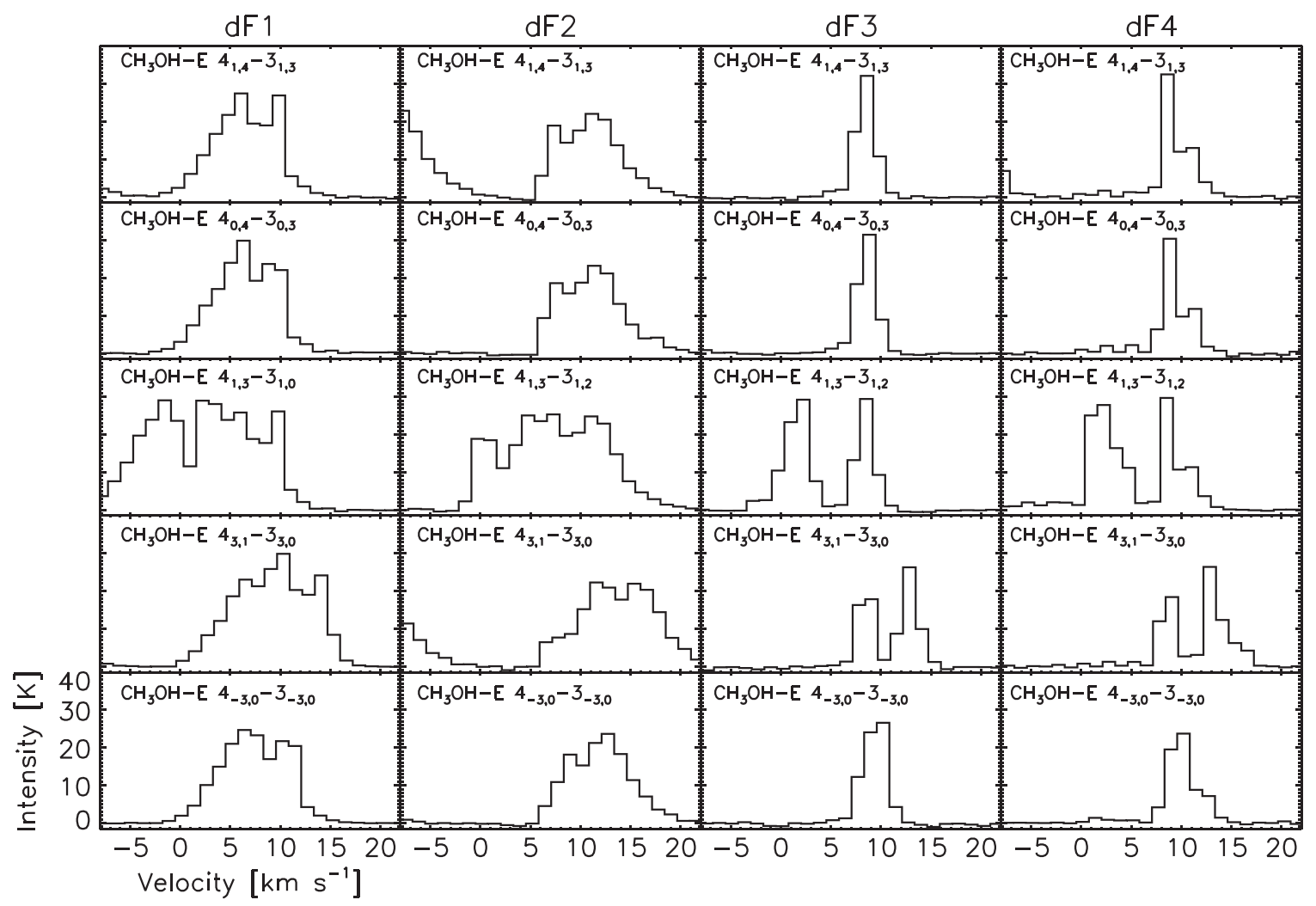

Figure 6. $\mathrm{CH}_{3} \mathrm{OH}-\mathrm{E}$ spectra observed toward $\mathrm{dF} 1, \mathrm{dF} 2, \mathrm{dF} 3$, and $\mathrm{dF} 4$.

Collings et al. 2004; Green et al. 2009). However, in the inner hottest part of Orion-KL where methanol emits, most of the formaldehyde might have been converted into methanol by grain-surface reactions (Watanabe \& Kouchi 2002) during a colder phase prior to the explosive event. Then, upon heating, methanol is released from grain surfaces into the gas phase along with little formaldehyde. We stress that the release of methanol into gas phase in this region is mainly due to internal radiation heating (i.e., outflow, shock, IR sources) but not heat from the PDR (see Section 4.2). In this instance, the D/H ratio and the spatial distribution of methanol should differ from that of formaldehyde.

\section{CONCLUSIONS}

We have characterized, for the first time, the spatial distribution of deuterated formaldehyde (HDCO) toward Orion-KL with an angular resolution of 3 ". $4 \times 3$ ". 0 using the SMA. The new SMA broadband capability of the $230 \mathrm{GHz}$ band allowed simultaneous observation of both HDCO and $\mathrm{H}_{2}{ }^{13} \mathrm{CO}$ within relatively sparse spectra. Four main emission peaks, labeled in this study $\mathrm{dF} 1$ to $\mathrm{dF} 4$, are identified in the formaldehyde emission image. An important result is that the spatial distribution the emission of the $\mathrm{HDCO}$ and $\mathrm{H}_{2}{ }^{13} \mathrm{CO}$ emission differ from that of $\mathrm{CH}_{3} \mathrm{OH}$ and its deuterated isotopologues. The emission maps show that methanol emits in the inner part of Orion-KL, while formaldehyde is found in the colder gas enveloping the $\mathrm{CH}_{3} \mathrm{OH}$ emission on four sides: one located left of the Hot Core $(\mathrm{dF} 1)$, one toward the north of the Compact Ridge $(\mathrm{dF} 2)$, and two in the quiescent ridge $(\mathrm{dF} 3$ and $\mathrm{dF} 4$ ). In addition, we derive a $\mathrm{HDCO} / \mathrm{H}_{2} \mathrm{CO}$ ratio which lies in the range $0.003-0.009$ within the region; this value is an order of magnitude higher than the $\mathrm{D} / \mathrm{H}$ measured for methanol. We suggest that the high measured $\mathrm{D} / \mathrm{H}$ ratio for formaldehyde and its spatial distribution in Orion-KL are a combination of gas-phase chemistry in the cooler gas associated with Orion-KL, and a conversion of formaldehyde into methanol on ice grain mantles in the earlier history of the inner part.

Support for this work was provided by NASA (Herschel OT funding) through an award issued by JPL/Caltech. This paper makes use of SMA data. C.F. thanks Tzu-Cheng Peng for helpful discussions.

Facility: SMA.

\section{REFERENCES}

Bally, J., Cunningham, N. J., Moeckel, N., et al. 2011, ApJ, 727, 113 Bergin, E. A., Goldsmith, P. F., Snell, R. L., \& Ungerechts, H. 1994, ApJ, 431, 674

Bergin, E. A., Phillips, T. G., Comito, C., et al. 2010, A\&A, 521, L20 Beuther, H., Zhang, Q., Greenhill, L. J., et al. 2005, ApJ, 632, 355 Beuther, H., Zhang, Q., Reid, M. J., et al. 2006, ApJ, 636, 323 Blake, G. A., Sutton, E. C., Masson, C. R., \& Phillips, T. G. 1987, ApJ, 315,621

Bocquet, R., Demaison, J., Cosléou, J., et al. 1999, JMoSp, 195, 345

Brouillet, N., Despois, D., Baudry, A., et al. 2013, A\&A, 550, A46

Cazaux, S., Caselli, P., \& Spaans, M. 2011, ApJL, 741, L34

Charnley, S. B., Tielens, A. G. G. M., \& Rodgers, S. D. 1997, ApJL, 482, L203

Collings, M. P., Anderson, M. A., Chen, R., et al. 2004, MNRAS, 354, 1133

Comito, C., Schilke, P., Phillips, T. G., et al. 2005, ApJS, 156, 127

Crockett, N. R., Bergin, E. A., Neill, J. L., et al. 2014, ApJ, 787, 112

Crockett, N. R., Bergin, E. A., Wang, S., et al. 2010, A\&A, 521, L21+

Esplugues, G. B., Tercero, B., Cernicharo, J., et al. 2013, A\&A, 556, A143

Favre, C., Bergin, E. A., Cleeves, L. I., et al. 2015, ApJL, 802, L23

Favre, C., Carvajal, M., Field, D., et al. 2014, ApJS, 215, 25

Favre, C., Despois, D., Brouillet, N., et al. 2011a, A\&A, 532, A32 
Favre, C., Wootten, H. A., Remijan, A. J., et al. 2011b, ApJL, 739, L12

Friedel, D. N., \& Snyder, L. E. 2008, ApJ, 672, 962

Friedel, D. N., \& Widicus Weaver, S. L. 2012, ApJS, 201, 17

Fuchs, G. W., Cuppen, H. M., Ioppolo, S., et al. 2009, A\&A, 505, 629

Goddi, C., Greenhill, L. J., Humphreys, E. M. L., Chandler, C. J., \& Matthews, L. D. 2011a, ApJL, 739, L13

Goddi, C., Humphreys, E. M. L., Greenhill, L. J., Chandler, C. J., \& Matthews, L. D. 2011b, ApJ, 728, 15

Goldsmith, P. F., \& Langer, W. D. 1999, ApJ, 517, 209

Gómez, L., Rodríguez, L. F., Loinard, L., et al. 2005, ApJ, 635, 1166

Gómez, L., Rodríguez, L. F., Loinard, L., et al. 2008, ApJ, 685, 333

Green, S. D., Bolina, A. S., Chen, R., et al. 2009, MNRAS, 398, 357

Guélin, M., Brouillet, N., Cernicharo, J., Combes, F., \& Wooten, A. 2008, Ap\&SS, 313, 45

Guzmán, V. V., Goicoechea, J. R., Pety, J., et al. 2013, A\&A, 560, A73

Hidaka, H., Watanabe, N., Shiraki, T., Nagaoka, A., \& Kouchi, A. 2004, ApJ, 614, 1124

Ho, P. T. P., Moran, J. M., \& Lo, K. Y. 2004, ApJL, 616, L1

Irvine, W. M., Goldsmith, P. F., \& Hjalmarson, A. 1987, in Chemical Abundances in Molecular Clouds, ed. D. J. Hollenbach \& H. A. Thronson, Jr. (Astrophysics and Space Science Library, Vol. 134; Dordrecht: D. Reidel), 56

Jacq, T., Walmsley, C. M., Henkel, C., et al. 1990, A\&A, 228, 447

Jacq, T., Walmsley, C. M., Mauersberger, R., et al. 1993, A\&A, 271, 276

Johns, J. W. C., \& McKellar, A. R. W. 1977, JMoSp, 64, 327

Kahane, C., Lucas, R., Frerking, M. A., Langer, W. D., \& Encrenaz, P. 1984, A\&A, 137, 211

Le Teuff, Y. H., Millar, T. J., \& Markwick, A. J. 2000, A\&AS, 146, 157

Lerate, M. R., Yates, J., Viti, S., et al. 2008, MNRAS, 387, 1660

Leurini, S., Parise, B., Schilke, P., Pety, J., \& Rolffs, R. 2010, A\&A, 511, A82

Leurini, S., Rolffs, R., Thorwirth, S., et al. 2006, A\&A, 454, L47

Loren, R. B., \& Wootten, A. 1985, ApJ, 299, 947

Maret, S., Ceccarelli, C., Caux, E., et al. 2004, A\&A, 416, 577

Maret, S., Ceccarelli, C., Tielens, A. G. G. M., et al. 2005, A\&A, 442, 527

Mauersberger, R., Henkel, C., Jacq, T., \& Walmsley, C. M. 1988, A\&A, 194, L1

Menten, K. M., Reid, M. J., Forbrich, J., \& Brunthaler, A. 2007, A\&A, 474,515

Müller, H. S. P., Gendriesch, R., Margulès, L., et al. 2000, PCCP, 2, 3401

Müller, H. S. P., Schlöder, F., Stutzki, J., \& Winnewisser, G. 2005, JMoSt, 742,215
Neill, J. L., Crockett, N. R., Bergin, E. A., Pearson, J. C., \& Xu, L.-H. 2013a, ApJ, 777, 85

Neill, J. L., Wang, S., Bergin, E. A., et al. 2013b, ApJ, 770, 142

Nissen, H. D., Cunningham, N. J., Gustafsson, M., et al. 2012, A\&A, 540, A119

Öberg, K. I., Qi, C., Wilner, D. J., \& Hogerheijde, M. R. 2012, ApJ, 749, 162

Pagani, L., Salez, M., \& Wannier, P. G. 1992, A\&A, 258, 479

Peng, T.-C., Despois, D., Brouillet, N., Parise, B., \& Baudry, A. 2012, A\&A, 543, A152

Peng, T.-C., Despois, D., Brouillet, N., et al. 2013, A\&A, 554, A78

Persson, C. M., Olofsson, A. O. H., Koning, N., et al. 2007, A\&A, 476,807

Qi, C. 2007, AdSpR, 40, 639

Remijan, A. J., Markwick-Kemper, A., \& ALMA Working Group on Spectral Line Frequencies 2007, BAAS, 38, 963

Rodríguez, L. F., Poveda, A., Lizano, S., \& Allen, C. 2005, ApJL, 627, L65

Rodriguez Kuiper, E. N., Kuiper, T. B. H., \& Zuckerman, B. 1978, ApJL, 219, L49

Roueff, E., Gerin, M., Lis, D. C., et al. 2013, JPCA, 117, 9959

Schilke, P., Benford, D. J., Hunter, T. R., Lis, D. C., \& Phillips, T. G. 2001, ApJS, 132, 281

Schilke, P., Groesbeck, T. D., Blake, G. A., \& Phillips, T. G. 1997, ApJS, 108, 301

Stahl, O., Casassus, S., \& Wilson, T. 2008, A\&A, 477, 865

Taquet, V., Ceccarelli, C., \& Kahane, C. 2012, ApJL, 748, L3

Tercero, B., Cernicharo, J., Pardo, J. R., \& Goicoechea, J. R. 2010, A\&A, 517, A96

Tercero, B., Vincent, L., Cernicharo, J., Viti, S., \& Marcelino, N. 2011, A\&A, 528, A26

Turner, B. E. 1990, ApJL, 362, L29

Turner, B. E., Fourikis, N., Morris, M., Palmer, P., \& Zuckerman, B. 1975, ApJL, 198, L125

Walmsley, C. M., Hermsen, W., Henkel, C., Mauersberger, R., \& Wilson, T. L. 1987, A\&A, 172, 311

Wang, S., Bergin, E. A., Crockett, N. R., et al. 2011, A\&A, 527, A95+

Watanabe, N., \& Kouchi, A. 2002, ApJL, 571, L173

Watanabe, N., Nagaoka, A., Shiraki, T., \& Kouchi, A. 2004, ApJ, 616, 638

Widicus Weaver, S. L., \& Friedel, D. N. 2012, ApJS, 201, 16

Wootten, A. 1987, in IAU Symp. 120, Astrochemistry, ed. M. S. Vardya \& S. P. Tarafdar (Dordrecht: D. Reidel), 311

Zapata, L. A., Schmid-Burgk, J., \& Menten, K. M. 2011, A\&A, 529, A24 